\title{
Store flyers: managing spatial distribution under budget constraints
}

\section{Beatrice Luceri, Fabrizio Laurini and Sabrina Latusi Department of Economics and Management, University of Parma, Parma, Italy}

\begin{abstract}
Purpose - The study develops a decision support system for the spatial distribution of store flyers, identifying a number of factors related to the demand and the competition influencing the complexities of their allocation to the target population.

Design/methodology/approach - The model was developed incorporating the insights found in existing marketing literature and bypassing the limitations of the managerial practices. To this end, an in-depth discussion with a panel of retailers was held. The model was tested in collaboration with a retail chain.

Findings - The proposed system is flexible and provides an almost endless array of solutions in accordance with the retailer's strategic approach to the market. It captures the key trade-offs that need to be made during the decision-making process of a retailer with limited marketing resources.

Practical implications - The traditional managerial approach, based on a set of operational steps, is overtaken by a model that systematically considers the interrelationships between the decision-making factors involved.

Originality/value - This is the first attempt to analyse spatial distribution of store flyers, a topic that has yet to be explored in retail marketing research. The paper conceptualises the key variables which affect the optimisation problem and reviews the different streams of extant research to obtain the appropriate insights.
\end{abstract}

Keywords Store flyer distribution, Spatial competitive models, Promotion strategy

Paper type Research paper

\section{Introduction}

Store flyers are an important medium for retailers of consumer packaged goods. They play a strategic role in generating store traffic and shaping regular customers' purchasing behaviour. Moreover, they are a flexible means to communicate the assortment and convey a good price positioning, which are key attributes of the store's image. Despite the increase in the use of digital tools to target promotion, consumers still maintain a solid preference on paper. As an example, over $60 \%$ of consumers continue to prefer the paper flyer as the channel to access retailers' offers.

Also the literature confirms that the paper flyer still works as an effective promotional tool. A recent study aiming to measure the effectiveness of print versus online store flyers showed that $80 \%$ of an Italian retail chain customers respond equally to both versions while $20 \%$ of the customers display a higher response to print (Ziliani et al., 2019). Consumers seem to derive significant levels of social value from paper flyers as they permit easy discussion of their content with relatives or friends, denoting an actual attachment to this medium. Moreover, print flyers are perceived as a mark of consideration on the part of the brand and the retailer (Simon, 2016; Simon and Andrews, 2015).

Thus, it is not surprising that retailers still rely on this tool, investing significant resources, both human and financial. The flyer unit cost is almost insignificant: on average, it

(c) Beatrice Luceri, Fabrizio Laurini and Sabrina Latusi. Published by Emerald Publishing Limited. This article is published under the Creative Commons Attribution (CC BY 4.0) licence. Anyone may reproduce, distribute, translate and create derivative works of this article (for both commercial and noncommercial purposes), subject to full attribution to the original publication and authors. The full terms of this licence may be seen at http://creativecommons.org/licences/by/4.0/legalcode
Spatial distribution of store flyers

Received 2 December 2019 Revised 3 January 2020 2 April 2020

3 April 2020

Accepted 18 May 2020

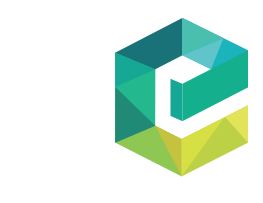

International Journal of Retail \& Distribution Management Vol. 48 No. 8, 2020 pp. $901-916$

Emerald Publishing Limited 0959-0552 
IJRDM 48,8 comes to a few cents to print and distribute a copy. However, if one considers the total number of copies being distributed, the perspective changes radically: according to European Letterbox Marketing Association (2016), 110bn flyers were distributed in 20 countries, for an estimated cost of 3.84bn euro for distribution alone.

In the face of these figures and trends, the optimisation of the paper flyer and its distribution will remain a focal point for retailers. Academic research has devoted attention to the effect on brand and store performance of flyers design and composition aspects (e.g. Freo, 2005; Gázquez-Abad and Martínez-López, 2016; Gijsbrechts et al., 2003; Pentus et al., 2018; Prediger et al., 2018). Instead, no study has been carried out to examine the underlying marketing and operational decisions behind the distribution of store flyers. This issue cannot be addressed relying on a micro-marketing approach until flyers are distributed in a mass manner.

Therefore, the objective of the paper is to develop and test a decision support system for flyers' distribution planning within a given store format and market area. Current trends in marketing support this objective. Specifically, this study echoes the recent call for a high recognition of business goal during model development (e.g. Lessmann et al., 2019).

The model has been designed to maximise the efficacy of such a distribution in the face of budget constraints. When marketing resources are inadequate to allocate a number of flyers equal to the number of households in the market area, the proposed system is able to determine the census tracts (the minimum geographical unit used for census purposes; in Italy, there are 402,677 census tracts) in which the flyer is to be distributed to the residing households and the census tracts in which it is not. It accomplishes this by establishing the combination of the census tracts that maximises the retailer's capacity to achieve its promotional objectives (supporting store patronage by customers and attracting noncustomers), given the characteristics of the demand and the competition in the considered market area. In so doing, the system does not abstract away from the key reality aspects of the distribution problem by identifying and incorporating a number of criteria that influence the optimisation of store flyers' spatial coverage. Moreover, it overcomes some of the limits of the traditional managerial practices which do not consider the relationships between the decision factors globally. As a rule, retailers plan the distribution of the store flyers store by store, based on the households density in each catchment area. This practice is largely used to minimise the logistics costs, but does not take into account the fact that consumers may patronise multiple stores. Moreover, such an approach does not capture the actual sales potential of the market. Thus, there is a need for a reliable decision support system to help retailers align their store flyer spatial allocation decisions with marketing principles.

By addressing a topic thus far unexplored and related to a medium that represents the majority of retailers' promotional budgets, the paper contributes to the existing retail marketing literature in two main ways. Its chief contribution is the conceptualisation of key variables that affect the optimisation problem of the spatial distribution of store flyers. The second contribution is the systematisation of the extant academic research with an interdisciplinary perspective in order to obtain the appropriate insights on a topic thus far neglected.

Given the widespread use of store flyers and the magnitude of the money spent on them, the expected managerial implications of this study are relevant. Firstly, the decision support system is flexible and provides an almost endless array of solutions in accordance with the retailer's strategic approach to the market. Secondly, it is able to capture the concrete tradeoffs encountered by a retailer during the decision-making process when confronted with limited marketing resources. Lastly, the system can be applied globally, even if it has been developed for grocery stores.

The paper is organised as follows. The next section provides some background information. The subsequent sections focus on the proposed model development and the model evaluation results. Finally, concluding remarks are provided. 


\section{Literature background}

Academic research into the marketing and operational decisions concerning the distribution of store flyers is virtually non-existent. This section reviews three streams of extant literature from which insights into the optimal spatial coverage for store flyers can be derived. The first one reviews the published studies on store flyers and store performance; the second one relates to models of spatial competition between retailers; the third stream of literature surveys the relevant research from the area of retailers' geomarketing. The following discussion focusses on the more consistent contributions with the purpose of this study.

Feature promotions have drawn great interest from researchers and a stream of literature has focussed on the implications of advertised deals at the store level and on the effectiveness of the store flyer as a whole (e.g. Ailawadi and Harlam, 2009; Freo, 2005; Gijsbrechts et al., 2003; Luceri et al., 2014; Mimouni Chaabane et al., 2010; Prediger et al., 2018). These studies support the premise that store flyers have a positive impact on store performance (e.g. store traffic and sales) and provide useful guidelines for decisions on the promotions to be offered (e.g. the variety of featured purchasing options) and the way they should be communicated (e.g. the method used to signal the bargain price). In particular, the work by Luceri et al. (2014) used a store format approach to directly link consumer deal response behaviour to the effectiveness of the retailers' promotion. The study demonstrates that the optimal store flyer configuration is related to the store format, and the response to flyer promotion programmes varies across customer segments in relation to their degree of store loyalty (additional vs regular shoppers). A recent study by Kato and Hoshino (2019) highlighted that, while the own-store flyers have a positive impact on store performance, the competitors' ones have negative effect. It also showed that store flyers' effectiveness is related to store-specific factors and market area features.

Spatial analysis and spatial interaction models have held the attention of scholars, starting with the seminal proposition of Reilly (1929). The interest can be explained in light of the relationship between growth, location strategy and market response (e.g. Newing et al., 2018). Understanding how the location or acquisition of a new store affects demand is important for retailers who wish to optimise market coverage and minimise cannibalisation effects. Most of these studies are concerned with the notion of store attraction and are developed on the basis of the model introduced by Huff (1964) that overcomes the limitations associated with the Reilly-type model. Specifically, two dimensions of store attraction were considered: a) spatial accessibility and b) variety of the assortment offered. The first dimension is commonly operationalised as the distance of the store from consumers' residential area, while store size is generally used as a proxy of the second dimension. Subsequently, studies have focussed on the definition of a more comprehensive model. In particular, the assessment of the role of the store format spatial competitive interaction has shown that store attraction also depends on the inter-format competitive context (e.g. De Beule et al., 2014; Gonzáles-Benito et al., 2005).

Geographic information systems (GISs) have allowed retailers to geographically visualise data from both external and internal sources. The integration of geo-visualisation techniques and technologies within decision support activities allows retailers to exploit the information potential at different levels (Chhetri et al., 2017; Chen, 2007). Specifically, the spatial analysis of retail sales by category and across the entire portfolio of stores is facilitated (Hernandez, 2007; Murad, 2011; Rodríguez et al., 2017). If the use of GIS is widespread among major retailers, the literature is thwarted by the difficulty in accessing retailers' databases on consumers and their spatial behaviour (Hanaoka and Clarke, 2007).

\section{Model development: conceptual framework}

The model has been developed to incorporate the insights from the existing literature and to overcome the limitations of the retailers' managerial practices. It embraces four

\section{Spatial distribution of store flyers}

903 
IJRDM 48,8

904

methodological premises: (1) the use of standardised and comprehensible econometric tools; (2) the adoption of objective measures based on loyalty card data and other typically easy-togather secondary data; (3) the use of the geomarketing approach to relate customers' internal data and markets' external data to territory (geo-referenced data); (4) the assumption of the overall store network within a specific store format (e.g. hypermarket, supermarket, superstore; (5) and market area for the basis of optimisation.

The first two aspects are critical to the adoption of quantitative models by retail managers (Simkin, 1996). The third one allows retailers to exploit the information potential of internal loyalty card data, which shows who the customers are and the details of their buying behaviour (where, when, how much and what they purchase; e.g. (Byrom, 2001), and enables them to include local factors in the analysis (store locations, trading area characteristics and competition; e.g. Bradlow et al., 2017). The last point deserves a more in-depth explanation. Retailers usually decide on the flyers' distribution store by store, relying on simple methods as experience or analogies (Lugli, 2017). Conversely, the model points to a shift from a store to a retail chain network (e.g. Rodríguez et al., 2017) in regard to a specific store format (e.g. Luceri et al., 2014) and market area (e.g. Kato and Hoshino, 2019). This is consistent with the marketing perspective that informs flyers' composition decisions (e.g. size of the flyer, value of the featured promotions, product categories and brands featured (Gijsbrechts et al.,2003). It is noteworthy that these decisions are made on the basis of store format differentiation and market area characteristics in terms of consumers and competitors. Therefore, multiple stores of the same retail chain operating within a specific store format and within a homogeneous market area share the same flyer because they share the same assortment and the same pricing policy (Luceri et al., 2014). The network approach, complemented by a store format and market area view, is also appropriate for the following reasons: (1) the catchment areas of the various stores may overlap; (2) the loyalty cards' circularity promotes customers' multistore patronage of a specific retail chain; (3) the retail chain stores within a specific local market face the same competitors.

The retailer's decisional problem is the optimisation of the distribution of a given number of store flyers. Such a number is determined to be the ratio of the marketing spending allocated to this communication lever and flyers' printing and distribution unit cost (net of fixed costs of flyers' design). This problem arises when marketing resources are not adequate to distribute a number of flyers equal to the number of households in the considered market.

The model resolves the decisional problem within a market area whose boundaries are defined by placing the retail chain customers on the territory through their home addresses. This is possible thanks to the use of loyalty card information combined with geographical software (Murad, 2011). The flyers' distribution area is therefore defined as the sum of the effective catchment areas of the stores the retailer runs in a given market area and store format. The approach proposed herein overcomes the limitations found in the more common models (i.e. isochrone, isodistance and radial) that define the store catchment area theoretically (Dennis et al., 2002).

The census tract is used as the minimum geographical unit to link the internal data set (loyalty card information), the exogenous information concerning the demand (number of households and inhabitants, grocery expenditure per capita) and the competition (number and selling area of competing modern stores by store format) to the same geographical scale. This spatial disaggregation allows to achieve a twofold objective: on the one hand, making marketing decisions based on the in-depth spatial analysis of local market conditions; on the other hand, the advantage of flexibility in planning the logistical process of door-to-door flyer drops.

The model is based on the optimisation of a $0-1$ normalised ranking of the census tracts in the considered market area (as previously defined). The rank for each census tract is modelled here as a function of its (1) importance and (2) attractiveness (Figure 1). 

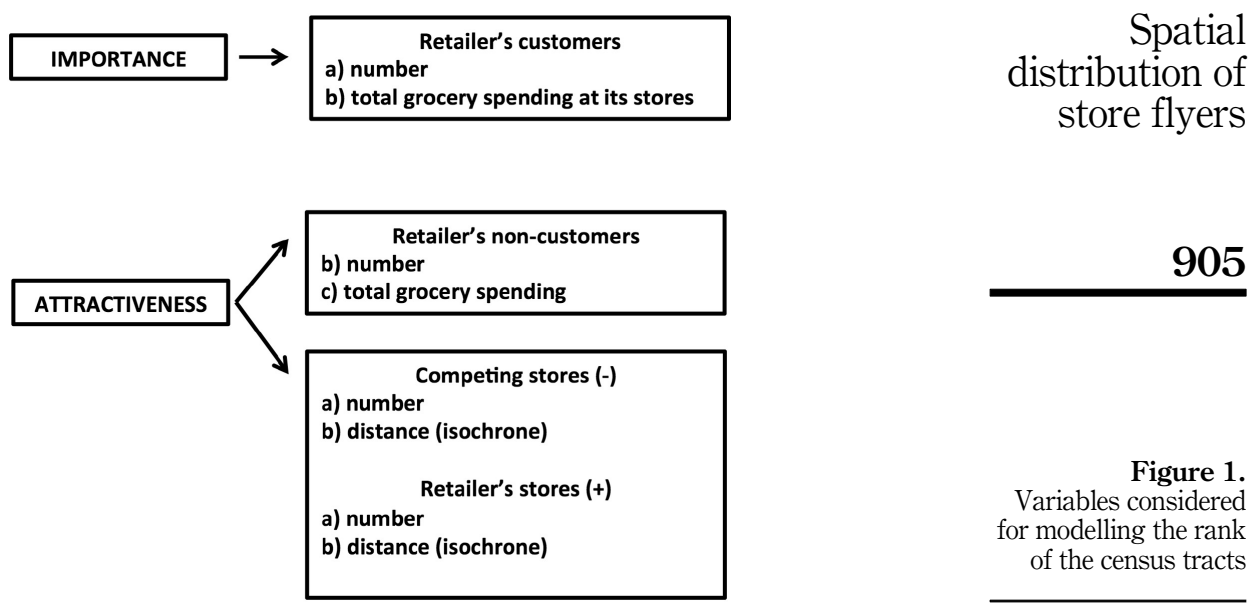

905

Figure 1.

Variables considered for modelling the rank of the census tracts

The importance captures the current economic relevance of the census tract for the retailer (Lugli, 2017). This factor explicitly considers the number of the retail chain customers residing in the census tract and their total grocery spending at its stores. Thus, it is assumed that the greater the number of customers and their expenditure, the greater the importance of that census tract for the retailer.

The attractiveness measures the growth opportunities for the retail chain in the census tract. This indicator takes the characteristics of both the demand and the competition (Pellegrini, 2014) into account.

First, the larger the number of non-customers and their expenditure, the greater the census tract attractiveness for the retailer. Therefore, attractiveness is measured considering the number of inhabitants residing in the census tract who are non-customers of the retailer and their total grocery spending.

Second, the larger the number of competing stores among which the inhabitants of a census tract can choose and the closer they are to the census tract, the less its attractiveness for the retailer. Specifically, the census tract can fall in the catchment area of one or more competing stores that, in turn, can be more or less close to the census tract. Thus, the attractiveness of the census tract for the retailer is minimal when it belongs to the first isochrones of all of the competing stores, whereas the attractiveness is maximal when the census tract does not fall in the catchment area of any of the competing stores. These are, of course, extreme conditions. Both inter- and intra-format competitors must be considered (e.g. Castaldo et al., 2013; De Beule et al., 2014; Gonzáles-Benito et al., 2005).

At the same time, the attraction power of the retail chain stores on the inhabitants of the census tract must be considered to assess the census tract attractiveness. The census tract can fall in the catchment area of one or more stores managed by the retailer that, in turn, can be closer to or further from the census tract. Therefore, the attractiveness of the census tract for the retailer is minimal when it does not fall in the catchment area of any of its stores, and vice versa, the attractiveness is maximal when the census tract belongs to the first isochrones of all its stores. Once again, these are extreme conditions.

The catchment area of both the competing stores and the retail chain network stores is defined in the model considering that their attraction power is influenced by the distance, the store format and the store size (i.e. Levy et al., 2013; McGoldrick, 2002). A store's ability to attract customers increases with the breadth and depth of merchandise offered. The first element is related to the store format and the second to the store selling area. With store 
IJRDM 48,8

906

format and store size being equal, the power of store attraction over demand is inversely proportional to the distance; specifically, it is maximal in the so-called primary zone and decreases as it shifts to the secondary zone, tertiary zone and so on. In the model, the distance measurement is defined as the minutes needed to reach the store by car or foot, according to the proximity service offered by the store (Table 1).

The objective function is optimised with a linear programming algorithm, as in (Vairaktarakis, 1999), and it is subject to the following constraints. First, store flyers must be distributed to all the households residing in a given census tract (Lugli, 2017). Indeed, there are no objective parameters to decide which households the store flyer is to be distributed to and which it will not. Thus, in the model, the store flyer is distributed to all of the households in a given census tract or is not distributed at all. The second constraint is introduced to incorporate the retailer's strategic approach to the market into the model (e.g. Castaldo et al., 2013; Gauri et al., 2017). Priority can be given to the current or the potential market. In the first case, the retailer focusses on customers and protects the demand already conquered from the shares of competitors; in the second case, the retailer focusses on non-customers and tries to win market share. In other words, in the first case, priority is given to the importance of census tracts, and in the second case, to their attractiveness. It is possible to view this as a continuum from a completely defensive approach (where the attractiveness is not considered) to a completely attacking one (where importance is not considered). It is the retailer who decides the positioning along such a continuum and this decision can change over time. Thus, the proposed model can be seen as a dynamic programming model.

\section{Model development: mathematical formulation}

Importance and attractiveness of a census tract $g$ are measured with variables having different nature and size. These variables are jointly normalised in the range $[0,1]$. The normalisation has the further benefit in the subsequent linear programming problem, allowing a unique finite solution.

It is assumed that the retailer has $j=1, \ldots, J$ stores into the market area with census tracts $g=1, \ldots, G$. The intra-format competing stores are $k=1, \ldots, K$, whereas the interformat competing stores are $l=1, \ldots, L$. Among the $L$ inter-format competing stores, there may be stores managed by the retailer in formats other than the one considered for the optimisation.

The attractiveness of a census tract: the retailer's stores

Stores have different distances from each census tract and in the model a discrete proximity $p$ is used, unlike in Gonzáles-Benito et al. (2005) where the Euclidean distance is considered. The proximities represent classes of distances in time from each census tract to a specific store, as reported in Table 1 . Formally, for a specific census tract $g$, the proximity to the retailer's $j$-th store is:

Table 1.

Catchment area and isochrones by store format and selling area

\begin{tabular}{lllllll}
\hline & & \multicolumn{4}{c}{ Isochrones (minutes by car or on foot) } \\
Store format & Selling area (square meters) & Reached & I & II & III & IV \\
\hline \multirow{2}{*}{ Hypermarket } & $\geq 5000$ & by car & $0-10$ & $>10-20$ & $>20-30$ & $>30-40$ \\
& $<5000$ & by car & $0-7$ & $>7-14$ & $>14-21$ & $>21-28$ \\
Superstore & $\geq 2500$ & by car & $0-5$ & $>5-10$ & $>10-15$ & $>15-20$ \\
Supermarket & $1,300-2,499$ & by car & $0-3$ & $>3-6$ & $>6-9$ & $>9-12$ \\
& $800-1,299$ & on foot & $0-4$ & $>4-8$ & $>8-12$ & $>12-16$ \\
& $400-799$ & on foot & $0-2$ & $>2-5$ & $>5-7$ & $>7-10$
\end{tabular}

Source(s): Authors' elaboration 


$$
p(j ; g), j=1, \ldots, J, \quad g=1, \ldots, G .
$$

Proximities and distances are inversely proportional, so large values of $p$ correspond to small distances. For a census tract $g$, stores have different proximities; hence, the overall proximity store flyers index for the census tract $g$ averages all these proximities. The maximum proximity, used for normalisation, is:

$$
\delta_{f}=\max _{g}\{p(1 ; g), p(2 ; g), \ldots, p(J ; g)\}
$$

The quantity $\delta_{f}$ is thus constant for all census tracts $g=1, \ldots, G$, representing the closest distance to one or more stores. Stores too far have proximity equal to zero.

Introducing the indicator function 1 , the following index is used:

$$
1_{p(j: g)}=1_{(j: g)}= \begin{cases}1 & \text { if the } j \text {-th store and the } g \text {-th census tract have } p>0 \\ 0 & \text { otherwise. }\end{cases}
$$

The probability that a census tract $g$ patronises any of the $J$ store is equal to the average proximity, compared to the closest possible retailer's store to any census tract for the whole market area, adjusted with the total number of the retailer's stores. Formally, such probability is:

$$
I_{f}^{g}=\frac{\sum_{j=1}^{J} p(j ; g) 1_{(j ; g)}}{J \times \delta_{f}}, g=1, \ldots, G .
$$

Note that in the numerator of probability in expression (1), the sum of proximities is not fixed for all census tracts. In the denominator, $J$ has been included to have a proper normalisation.

For a census tract $g$, by construction $I_{f}^{g} \in(0,1]$, with extremes occurring under the two most extreme conditions discussed further. The index used in expression (1) is close to zero when almost all of the retailer's stores are very far from the specific census tract $g$. Conversely, if all the retailer's stores are in the closest possible position to a specific census tract $g$, then $I_{f}^{g}=1$. Index in expression (1) can be close to zero when only a small proportion of the retailer's stores exert an attraction on a census tract $g$.

\section{Reducing the attractiveness of a census tract: the competing stores}

The build-up of probabilities in (1) can be extended to the competing stores. For the intraformat competing stores, proximities are denoted by:

$$
p(k ; g), k=1, \ldots, K, g=1, \ldots, G .
$$

With such proximities, the probability that any of the $K$ competing store is visited by the households residing in a census tract $g$ (for the intra-format competition) is given by the formula:

$$
I_{c}^{g}=\frac{\sum_{k=1}^{K} p(k ; g) 1_{(k: g)}}{K \times \delta_{c}}, g=1, \ldots, G,
$$

which takes values following the same arguments used when interpreting $I_{f}^{g}$, but now focussed on the intra-format competition. Again, the number of stores affecting a specific census tract $g$ is not fixed for all census tracts. Hence, it may occur that for some of the $K$ stores, the proximity to a census tract $g$ collapses to zero, meaning that none of the $K$ store has any patronage for the census tract $g$. 
IJRDM

48,8

908

For the inter-format competing stores, proximities are:

$$
p(l ; g), l=1, \ldots, L, \quad g=1, \ldots, G .
$$

The probability that any of the $L$ inter-format competing store is visited by the households living in a census tract $g$ is given by:

$$
I_{s}^{g}=\frac{\sum_{l=1}^{L} p(l ; g) 1_{(l ; g)}}{L \times \delta_{s}}, g=1, \ldots, G
$$

with a similar interpretation of $I_{f}^{g}$ and $I_{c}^{g}$.

For the competing stores, the probabilities $I_{c}^{g}$ and $I_{s}^{g}$ are combined. A sensible approach is to use:

$$
I^{g}=I_{c}^{g} \times I_{s}^{g} .
$$

The joint probability (2) is proportional to the strength of the competition in the census tract $g$. Higher values of $I^{g} \in[0,1]$ for census tract $g$ are associated with conditions of severe competition, as the retailer's stores must face competition with (a roughly) similar number of competing stores regardless of format. Values of probability (2) close to zero are associated with either negligible inter-format competition or negligible intra-format competition (or both).

The attractiveness of a census tract: the retailer's non-customers

The attractiveness of a census tract $g$ is linked to the total number of the retailer's noncustomers and their total grocery spending. The two variables are labelled as $x_{t}(n ; g)$ and $x_{t}(r ; g)$, respectively, and have different order/size and distribution. Since no absolute upper bound can be used for normalisation, the construction of indices exploits the sample correlation between $x_{t}(n ; g)$ and $x_{t}(r ; g)$. The remarkable correlation between two variables becomes a model assumption in the sequel.

\section{The importance of a census tract}

The importance of each census tract $g$ is obtained by combining the number of current customers of the retailer's stores and their total grocery spending for all stores $j=1, \ldots, J$. The retailer's overall number of customers is denoted by $x_{f}(n ; g)$ and their total grocery spending by $x_{f}(r ; g)$, and they have strong empirical correlation. Again, this is becoming a model assumption.

\section{Factor analysis, smoothing and normalisation}

Exploiting the large correlation between the variables, univariate indicators are created via factor analysis (Skipper and Hanna, 2009). For the importance and the attractiveness, the first principal component is:

$$
y^{g}=a_{1} x_{f}(r ; g)+a_{2} x_{f}(n ; g) \text { and } w^{g}=b_{1} x_{t}(r ; g)+b_{2} x_{t}(n ; g) .
$$

Each first component is the realisation of the underlying variable $Y^{g}$ and $W^{g}$, with smooth distribution functions $\widehat{F}_{Y^{g}}$ and $\widehat{F}_{W^{g}}$. Details for $\widehat{F}_{Y^{g}}$ are shown, but similar arguments hold for $\widehat{F}_{W^{g}}$. The expression for $\widehat{F}_{Y^{g}}$ is:

$$
\widehat{F}_{Y^{g}}(r)=\int_{-\infty}^{r} \widehat{f}_{Y^{g}}(t) d t
$$


The integral $\widehat{F}_{Y^{g}}$ is evaluated numerically by first fitting a spline to the kernel density function $f_{Y^{g}}$, estimated by:

$$
\widehat{f}_{Y^{g}}(r)=\frac{1}{G h} \sum_{g=1}^{G} \Phi\left(\frac{r-Y^{g}}{h}\right),
$$

where $\Phi$ is the Gaussian kernel and $h$ the smoothing bandwidth parameter, chosen to minimise the mean integrated squared error.

With the smooth distribution function (3), the census tracts are ranked in the interval $[0,1]$, with the more important census tracts having a value closer to 1 . Hence, $\widehat{F}_{Y^{g}} \in[0,1]$ in (3) represents the importance of census tract $g$ for the retailer and is explicit function of the number of the retailer's customers and their total spending at its stores.

The build-up for the retailer's non-customers is $\widehat{F}_{W^{g}} \in[0,1]$, now playing the role of a measure of attractiveness of a census tract.

\section{Linear programming optimisation with flexible tuning parameters}

The standardisations of the indices of attractiveness and the non-parametric indices $\widehat{F}$ are simple to use and can be combined in a weighted mixture. The mixing of attractiveness and importance will be considered with a further set of tuning parameters. The optimal distribution of flyers will take into account the indices of importance of a census tract $g$, given by (3), and an overall index of attractiveness. As a summary of the overall level of attractiveness, each building brick has the same weight; this implies that the simple average is the most natural candidate, but other approaches are clearly possible. The overall score for attractiveness is:

$$
Z^{g}=\frac{I_{f}^{g}+\widehat{F}_{W^{g}}+\left(1-I^{g}\right)}{3}, \quad g=1, \ldots, G .
$$

Expression (4) is bounded in the interval $[0,1]$ with values of $Z^{g}$ close to 1 for census tract $g$ being most attractive (low level of competition, high number of non-customers). Focussing on the optimisation problem, it is necessary to select the census tracts where a number of $v_{g}$ flyers will be distributed. This problem is tackled with the following linear problem, which introduces four additional tuning parameters such that $\alpha_{i} \in[0,1], i=1, \ldots, 4, \alpha_{i} \geq 0$ and $\sum \alpha_{i}=1$ (Shukla et al., 2011) used a similar approach for tuning a trade-off between robustness and efficiency. The problem becomes:

$$
\begin{aligned}
\max & \sum_{g=1}^{G} \alpha_{4} \widehat{F}_{Y^{g}} v_{g}+\frac{1}{3}\left[\alpha_{1} I_{f}^{g} v_{g}+\alpha_{2} \widehat{F}_{W^{g}} v_{g}+\alpha_{3}\left(1-I^{g}\right) v_{g}\right] \\
\text { subject to } & \sum_{g=1}^{G} v_{g}=V \\
\text { and subject to } & \sum_{g=1}^{G} \pi_{g} v_{g} \leq C .
\end{aligned}
$$

The notation $n_{g}$ indicates the overall number of families living in a census tract $g$. The total number of flyers to be distributed is $V$, that is, an integer such that $V<\sum_{g} n_{g}$. A budget constraint is included, with $\pi_{g}$ representing the total cost of flyer distribution in a specific census tract $g$, and $C$ denotes the overall cost of distribution. In the model setup, it is assumed that the cost of distribution $\pi_{g}$ is constant for all census tracts. 
IJRDM 48,8

910

One consequence of the optimisation is that if $V<\sum_{g} n_{g}$, the distribution of flyers does not occur in all $G$ census tracts. But if a census tract is selected by the model, then the flyers will be distributed to all households, that is:

$$
v_{g}= \begin{cases}n_{g} & \text { if census tract } g \text { is selected } \\ 0 & \text { if census tract } g \text { is not selected. }\end{cases}
$$

For such a reason, it is unlikely that the equality $V=\sum n_{g}$ holds exactly (the constraint is over the sum of $v_{g}$ and not the sum of $n_{g}$ ), due to the selection of a sub-sample of census tracts. Minor rounding will be necessary in those cases, making the overall number of flyers distributed equal to $V \pm \epsilon$, with (small) $\epsilon>0$.

The tuning parameter is such that for $\alpha_{4}=0$, the retailer is "playing as forward" and is prioritising the attraction of non-customers rather than the retention of current customers. Conversely, for $\alpha_{4}=1$, the retailer is "playing defence", as the distribution will be mostly spread across areas where the retailer is already dominant.

A brief description of inputs used in the optimisation is reported in Table 2.

\section{Numerical analysis}

Settings for the test

The proposed model was discussed in-depth with a panel of grocery retailers operating in Italy who confirmed the conventional managerial practices used for flyer distribution. All the managers agreed on the capability of the proposed model to guarantee a more rigorous and marketing-oriented approach, especially when the number of flyers distributed must be reduced. In their opinion, spatial allocation that simultaneously considers the factors of the model would help to maximise store performance.

A leading retailer provided the data to test the model in the hypermarket format in a specific market area served with two stores of 6,000 and 4,500 square metres, respectively.

The distribution area was defined as the sum of the catchment areas of the two hypermarkets through the geocoding of the loyalty card customers' addresses. In this area there were 188,532 resident households (National Bureau of Census) and the retailer faced the competition of five superstores (15,979 square metres in total), 58 large and medium supermarkets (56,974 square metres in total), 73 small supermarkets (14,294 square metres in total) and 35 discount stores (22,175 square metres in total).

Summary of variables and parameters used in the optimisation

\begin{tabular}{ll}
\hline Notation used & Description and properties \\
\hline$J$ & Total number of stores of the retailer for which the optimal distribution of flyers is designed \\
$G$ & Total number of census tracts in the market area \\
$K$ & Total number of intra-format competing stores \\
$L$ & Total number of inter-format competing stores \\
$I_{f}^{g}$ & Proximity index $\in(0,1])$ for the $J$ retailer's stores (used to build attractiveness) \\
$I_{c}^{g}$ & Proximity index $\in(0,1])$ for the $K$ intra-format competing stores (used to build attractiveness) \\
$I_{s}^{g}$ & Proximity index $\in(0,1])$ for the $L$ inter-format competing stores (used to build attractiveness) \\
$I^{g}$ & Overall proximity index $\in(0,1])$ for the $K+L$ competing stores \\
$Y^{g}$ & First principal component for the importance of census tract \\
$W^{g}$ & First principal component for the attractiveness of census tract \\
$\widehat{F}_{Y g}$ & Kernel smooth distribution $\in(0,1)$ of $Y^{g}$ (used to define importance) \\
$\widehat{F}_{W^{g}}$ & Kernel smooth distribution $\in(0,1)$ of $W^{g}$ (used to build attractiveness) \\
$Z^{g}$ & Overall index of attractiveness \\
$V$ & Total number of flyers distributed \\
$\alpha_{i} \geq 0$ & Tuning parameters $\in[0,1]$ for a forward/defence strategy \\
$C$ & Overall cost of distribution \\
\hline
\end{tabular}


The marketing problem posed by the retailer was to reduce the number of flyers from 133,000 to $123,000(-8 \%)$, without losing sales and choosing an offensive strategic approach. The information of the annual grocery spending of the target population was obtained from the retailer's hypermarkets loyalty card database for its customers and the National Bureau of Census for non-customers.

The test lasted seven months (April-October 2017) and results were evaluated by comparing before-after actual sales on a monthly basis. Historical transaction data for the two hypermarkets were used since January 2005. The opening dates of three new competing stores were taken into account and coded with dummy impulse variables.

The sales were detrended and adjusted seasonally by a multiplicative SARIMA model (Arunraj et al., 2016), with the aim to contrasting the before-after sales without bias. The results, properly standardised by the baseline, were investigated with a $t$-test for differences of means.

\section{Time series of sales: fitted model and diagnostics}

The time series of $\log$-transformed sales $y_{t}$ and the fitted log-transform $\widehat{y}_{t}$ are jointly displayed in Figure 2 (black solid line and grey dashed line, respectively). The fit is very good, with an adjusted $R^{2}$ larger than 0.9 , and all model diagnostics hinting to an uncorrelated residual process.

\section{The reallocation of the target flyers in the market area}

The market area consists of $G=3,584$ census tracts located in Parma (Italy) and nearby suburbs and villages. The retailer's hypermarkets are labelled with a black dot in Figure 3, while the five intra-format competing stores and the 59 inter-format ones are not displayed for convenience.

The optimisation of (5) was achieved using GLPK; the budget constraint $C$ in euros is not reported for confidentiality reasons. The computation is limited to the special case of $\alpha_{1}=\alpha_{2}=\alpha_{3}=1 / 3$, that is, all of the indicators of attractiveness have equal weight. The retailer decided a purely "attacking" strategy and decided to set $\alpha_{4}=0$. In Figure 3 , the light

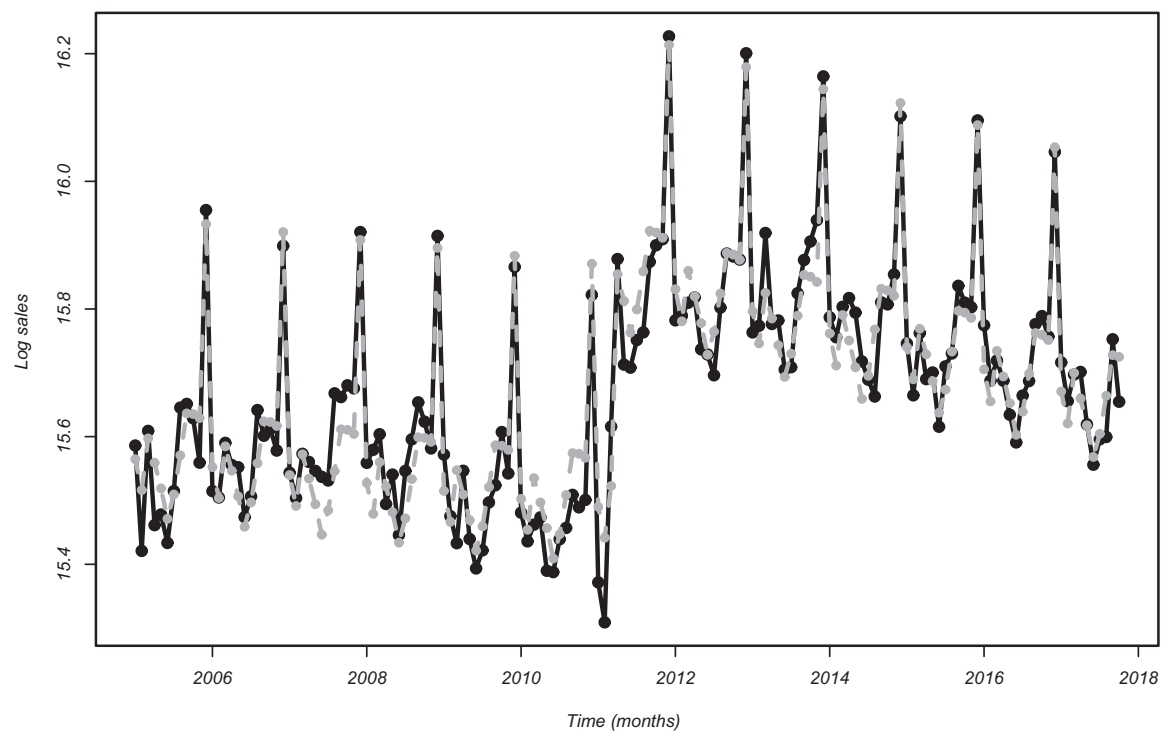

Spatial distribution of store flyers
Figure 2. Log-transform of sales (black continuous) and superimposed fitted ARIMA model (dark grey dashed) 


\section{IJRDM 48,8}

\section{2}

Figure 3.

The spatial

distribution of store

flyers before and after using the optimisation model

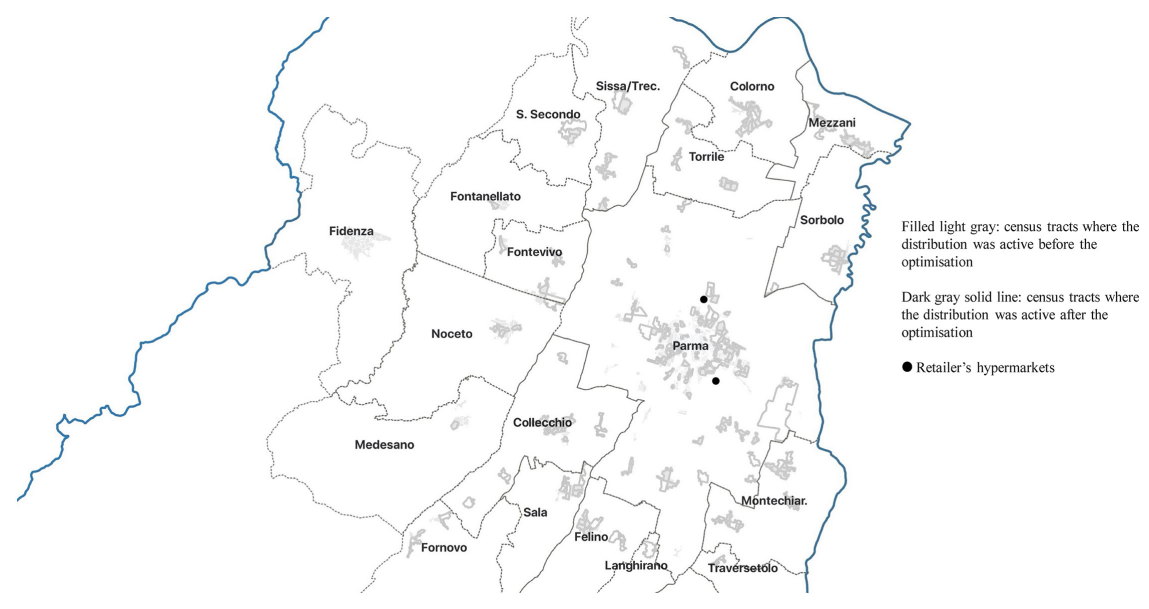

grey line and the dark grey solid one represent the census tracts where distribution was active before and after the optimisation, respectively.

The main finding is that some villages were no longer reached by the distribution process, mostly located in the north-west part of the market area. This is motivated by the reduction of the number of flyers distributed, but also by the attacking choice: census tracts where the competition is weak, or absent, were ruled out by the optimisation, independently from their distance to the two hypermarkets. These hypotheses are validated via proper statistical tools to get significant evidence.

\section{Comparison before-after on adjusted and standardised data}

With the fitted model, for each time period $t$, it is possible to assign to each census tract the estimated components of trend and seasonality, thus standardising the data of all census tracts. The performance of the model at census tract level can be evaluated by analysing the sales data of the retailer's customers with loyalty cards, since they can be geo-referenced through their home address. These data during the test period of seven months (AprilOctober 2017) were contrasted with those of over the same period during 2016. The comparisons were performed via several pairwise $t$-tests, adopting the conservative Bonferroni correction false discovery rate to avoid and compute the $p$-value suitably. The dependence is taken into account when computing the standard errors of estimates.

Results showed no significant difference before and after the reduction in the number and the reallocation of the flyers (Table 3 ).

An additional comparison was carried out for customers without loyalty cards. Since their spending cannot be tracked and referred to a specific census tract, data can be evaluated at an aggregate level only (store level). A model to take into account the trend, cycles and seasonality was fitted. Even for those customers, no significant difference was found before and after the reduction of the number of flyers.

In conclusion, despite the sensible reduction of the number of flyers, no significant reduction of sales emerged. Therefore, the model has successfully passed the test phase.

\section{Conclusion}

The objective of the paper was to propose and test a decision support algorithm for the spatial distribution of store flyers that accounts for retailers' objectives during model development 
(e.g. Lessmann et al., 2019). Several factors were taken into account to optimise this decision: the characteristics of the demand and the competition in a market area whose boundaries were defined as the sum of the catchment areas of all the retailer's stores in a specific format that share the same flyer. The test phase proved the validity of the model and its ability to enforce a rigorous decision-making process.

This is the first attempt to analyse the spatial distribution of store flyers, a topic unexplored in prior retail marketing research. The paper conceptualises the key variables that affect the optimisation problem and reviews the different streams of extant academic research with an interdisciplinary perspective in order to obtain the appropriate insights. Even if this study concentrates on mass distribution of store flyers, the algorithm does not exclude the aspect of micro-segmentation. The conditio sine qua non is the affordability of a personalised sending.

The managerial implications of the proposed model are also relevant, providing retailers with a reliable decision support system. The model is flexible, providing an almost endless array of solutions according to the retailer's strategic approach to the market. Specifically, the retailer can choose whether to focus on customers or non-customers; in other words, it is possible to define a specific orientation between retention and attraction objectives, which is valuable from both a strategic and tactical perspective. At the strategic level, it gives retailers the freedom to distribute store flyers according to changes in the marketing environment; at the tactical level, it allows retailers to promptly react to aggressive actions by competitors. The flexibility of the model is also useful for differentiating the management of flyers covering the same promotional period, but with different content and target populations. Consider, for example, a retailer who has planned a flyer dedicated to gardening in addition to the usual one featuring grocery products for its hypermarkets. In the first case, the marketing objective is to increase the share of wallet among actual customers and the model allows retailers to define the flyer's spatial distribution based on a defensive approach. In the second case, the marketing objective is to conquer new customers and the model allows retailers to define the flyer's spatial distribution based on an attacking approach. As a result, the model better captures the realistic decision environment faced by retailers, including several key aspects ignored by actual managerial practice.

The relevance of these managerial implications will remain important in the future, as retailers agree that paper flyers are compatible with digital promotional tools (Ziliani and Ieva, 2015). Moreover, they pursue complementary aims (Jensen et al., 2014): digital flyers allow for better targeting, they stimulate sharing among users and provide retailers with a good performance analysis instrument; paper flyers allow retailers to reach everyone, promote offers, generate interest and brand awareness as well as to maintain customer loyalty.

This study is constrained by limitations that point to areas for further future research. It would be interesting to investigate the case of retailers with marketing goals and distribution

\begin{tabular}{lccc}
\hline & $\begin{array}{c}\text { Monthly sales per capita } \\
\text { 2016 (Euro) }\end{array}$ & $\begin{array}{c}\text { Monthly sales per capita } \\
\text { 2017 (Euro) }\end{array}$ & $p$-value \\
\hline $\begin{array}{l}\text { Census tracts where flyers } \\
\text { optimistration) }\end{array}$ & 135 & 137 & 0.19 \\
$\begin{array}{l}\text { (2) were distributed after the } \\
\text { optimisation (not before) }\end{array}$ & 141 & 138 & 0.5 \\
$\begin{array}{l}\text { (3) were distributed before the } \\
\text { optimisation (not after) }\end{array}$ & 105 & 101 & 0.22 \\
$\begin{array}{l}\text { (4) were not distributed (before and after } \\
\text { the optimisation) }\end{array}$ & 136 & 135 & 0.41 \\
\end{tabular}
the optimisation)

\section{Spatial distribution of store flyers}

913 
IJRDM 48,8

issues different from those hitherto analysed. Moreover, the analysis of catchment areas, defined according to different types of gravitational models, is a further interesting avenue for research. Proximities do not consider multi-purpose and multi-destination shopping trips, but future research could improve such a measure. Finally, a promising topic is the evaluation of store network performance in the face of different strategic approaches to flyer distribution. What happens to the share of wallet, total sales, gross margins and store patronage when the retailer shifts from a defensive approach to an attacking one? This is just one of the possible questions related to store performance to which supplying an answer relying on the proposed model is valuable. It is believed that this study provides scholars and practitioners with the foundation and framework to systematically investigate market contexts very different from grocery retailing.

\section{References}

Ailawadi, K.L. and Harlam, B.A. (2009), "Retailer promotion pass-through: a measure, its magnitude, and its determinants", Marketing Science, Vol. 28 No. 4, pp. 782-791.

Arunraj, N., Sivanandam, D.A. and Fernandes, M. (2016), "Application of SARIMAX model to forecast daily sales in food retail industry", International Journal of Operations Research and Information Systems, Vol. 7 No. 2, pp. 1-21.

Bradlow, E.T., Gangwar, M., Kopalle, P. and Voleti, S. (2017), "The role of big data and predictive analytics in retailing", Journal of Retailing, Vol. 93 No. 1, pp. 79-95.

Byrom, J. (2001), "The role of loyalty card data within local marketing initiatives", International Journal of Retail and Distribution Management, Vol. 29 No. 7, pp. 333-342.

Castaldo, S., Grosso, M. and Premazzi, K. (2013), Retail and Channel Marketing, Edward Elgar Pub, Cheltenham.

Chen, R.J. (2007), "Geographic information systems (GIS) applications in retail tourism and teaching curriculum”, Journal of Retailing and Consumer Services, Vol. 14 No. 4, pp. 289-295.

Chhetri, P., Kam, B., Hung Lau, K., Corbitt, B. and Cheong, F. (2017), "Improving service responsiveness and delivery efficiency of retail networks: a case study of Melbourne", International Journal of Retail \& Distribution Management, Vol. 45 No. 3, pp. 271-291.

De Beule, M., Van den Poel, D. and Van de Weghe, N. (2014), "An extended Huff-model for robustly benchmarking and predicting retail network performance”, Applied Geography, Vol. 46, pp. 80-89.

Dennis, C., Marsland, D. and Cockett, T. (2002), "Central place practice: shopping centre attractiveness measures, hinterland boundaries and the UK retail hierarchy", Journal of Retailing and Consumer Services, Vol. 9 No. 4, pp. 185-199.

Freo, M. (2005), "The impact of sales promotions on store performance: a structural vector autoregressive approach”, Statistical Methods and Applications, Vol. 14 No. 2, pp. 271-281.

Gauri, D.K., Ratchford, B., Pancras, J. and Talukdar, D. (2017), “An empirical analysis of the impact of promotional discounts on store performance", Journal of Retailing, Vol. 93 No. 3, pp. 283-303.

Gázquez-Abad, J.C. and Martínez-López, F.J. (2016), "Understanding the impact of store flyers on purchase behaviour: an empirical analysis in the context of Spanish household", Journal of Retailing and Consumer Services, Vol. 28 No. January, pp. 263-273.

Gijsbrechts, E., Campo, K. and Goossens, T. (2003), "The impact of store flyers on store traffic and store sales: a geo-marketing approach", Journal of Retailing, Vol. 79 No. 1, pp. 1-16.

Gonzáles-Benito, O., Muñoz-Gallego, P.A. and Kopalle, P.K. (2005), "Asymmetric competition in retail store formats: evaluating inter- and intra-format spatial effects", Journal of Retailing, Vol. 81 No. 1, pp. 59-73.

Hanaoka, K. and Clarke, G.P. (2007), "Spatial microsimulation modelling for retail market analysis at the small-area level", Computers, Environment and Urban Systems, Vol. 31 No. 2, pp. 162-187. 
Hernandez, T. (2007), "Enhancing retail location decision support: the development and application of geovisualization”, Journal of Retailing and Consumer Services, Vol. 14 No. 4, pp. 249-258.

Huff, D.L. (1964), "Defining and estimating a trading area”, Journal of Marketing, Vol. 28 No. 3, pp. 34-38.

Jensen, B., Orquin, J. and Bech-Larsen, T. (2014), "What distinguishes passive recipients from active decliners of sales flyers?", Journal of Retailing and Consumer Services, Vol. 21 No. 1, pp. 1-8.

Kato, R. and Hoshino, T. (2019), "The impact of competitors' store flyer advertisements on EDLP/highSpatial
distribution of store flyers low chain performance in a highly competitive retail market: GPS information and pos data approach in Japan”, Journal of Advertising, Vol. 48 No. 5, pp. 569-587.

Lessmann, S., Haupt, J., Coussement, K. and De Bock, K.W. (2019), “Targeting customers for profit: an ensemble learning framework to support marketing decision-making", Information Sciences, pp. 1-16, doi: 10.1016/j.ins.2019.05.027, available at: https:/www.sciencedirect.com/science/ article/pii/S0020025519304268\#! (accessed 21 May 2019).

Levy, M., Weitz, B. and Grewal, D. (2013), Retailing Management, Irwin Professional Pub., New York.

Luceri, B., Latusi, S., Vergura, D.T. and Lugli, G. (2014), "The impact of store flyers on store performance: a format and customer related approach", International Journal of Retail and Distribution Management, Vol. 42 No. 3, pp. 219-234.

Lugli, G. (2017), Promotion Overload, Maggioli Editore, Santarcangelo di Romagna.

McGoldrick, P.J. (2002), Retail Marketing, McGraw-Hill, New York.

Mimouni Chaabane, A., Sabri, O. and Parguel, B. (2010), "Competitive advertising within store flyers: a win-win strategy?”, Journal of Retailing and Consumer Services, Vol. 17 No. 6, pp. 478-486.

Murad, A.A. (2011), "Creating a GIS application for retail facilities planning in jeddah city", Journal of Computer Science, Vol. 7 No. 6, pp. 902-908.

Newing, A., Clarke, G. and Clarke, M. (2018), "Applied spatial modelling for retail planning in tourist resorts", International Journal of Retail \& Distribution Management, Vol. 46 Nos 11/12, pp. 1117-1132.

Pellegrini, L. (2014), "Consumers' behaviour and producer-distributor relationships in convenience goods markets", in Reddy, S.K. and Pellegrini, L. (Eds), Retail and Marketing Channels, Routledge, New York, pp. 3-23.

Pentus, K., Ploom, K., Kuusik, A. and Mehine, T. (2018), "How to optimize sales flyers - novel experiment design”, Baltic Journal of Management, Vol. 13 No. 2, pp. 191-208.

Prediger, M., Huertas-Garcia, R. and Ga 'zquez-Abad, J.C. (2018), "How store flyers de- sign affect perceived variety of retailers' assortment”, Industrial Management \& Data Systems, Vol. 119 No. 2, pp. 382-396.

Reilly, W.J. (1929), Method for the Study of Retail Relationships, Research Monograph, University of Texas, Austin, Texas, Vol. 4.

Rodríguez, V., Olarte-Pascual, C. and Saco, M. (2017), "Application of geographical information systems for the optimal location of a commercial network", European Journal of Management and Business Economics, Vol. 26 No. 2, pp. 220-237.

Shukla, A., Agarwal Lalit, V. and Venkatasubramanian, V. (2011), "Optimizing efficiency-robustness trade-offs in supply chain design under uncertainty due to disruptions", International Journal of Physical Distribution \& Logistics Management, Vol. 41 No. 6, pp. 623-647.

Simkin, L. (1996), "Tackling barriers to effective implementation of modelling in retail marketing applications", International Review of Retail Distribution \& Consumer Research, Vol. 6 No. 3, pp. 225-241.

Simon, F. and Andrews, L. (2015), “A relational approach to direct mail consumption: the perspective of engagement regimes", European Journal of Marketing, Vol. 49 Nos 9/10, pp. 1527-1562. 
IJRDM 48,8

916
Simon, F. (2016), "Consumer adoption of no junk mail stickers: an extended planned behavior model assessing the respective role of store flyer attachment and perceived intrusiveness", Journal of Retailing and Consumer Services, Vol. 29, pp. 12-21.

Skipper, J.B. and Hanna, J.B. (2009), "Minimizing supply chain disruption risk through enhanced flexibility", International Journal of Physical Distribution \& Logistics Management, Vol. 39 No. 5 , pp. 404-427.

Vairaktarakis, G.L. (1999), "Optimization tools for design and marketing of new/improved products using the house of quality", Journal of Operations Management, Vol. 17 No. 6, pp. 645-663.

Ziliani, C. and Ieva, M. (2015), "Retail shopper marketing: the future of promotional flyers", International Journal of Retail andDistribution Management, Vol. 43 No. 6, pp. 488-502.

Ziliani, C., Ieva, M., Gázquez-Abad, J. and D’Attoma, I. (2019), "Retail promotional communication: the comparative effectiveness of print versus online", in Piotrowicz, W. and Cuthbertson, R. (Eds), Exploring Omnichannel Retailing, Springer, Cham, pp. 225-249.

\section{Corresponding author}

Beatrice Luceri can be contacted at: beatrice.luceri@unipr.it

For instructions on how to order reprints of this article, please visit our website: 